\title{
Surgical refinement of the purse-string suture for skin and soft tissue defects of the head and neck
}

\author{
Hyochun Park, \\ Yunjae Lee, \\ Hyeonjung Yeo, \\ Hannara Park \\ Department of Plastic and \\ Reconstructive Surgery, Daegu Fatima \\ Hospital, Daegu, Korea
}

\begin{abstract}
Background: The purse-string suture (PSS) is a simple and rapid wound closure method that results in minimal scarring. It has been used to treat circular or oval skin defects caused by tumor excision or trauma. However, due to obscurity, it is not widely used, especially for the head and neck. This study aimed to modify the PSS to obtain predictable and acceptable results.

Methods: A total of 45 sites in 39 patients with various types of skin and soft tissue defects in the head and neck were treated with PSS. We used PDS II (2-0 to 5-0), which is an absorbable suture. Minimal dissection of the subcutaneous layer was performed. The suture knot was hidden by placing it in the dissection layer. Depending on the characteristics of the skin and soft tissue defects, additional surgical interventions such as side-to-side advancement sutures, double PSS, or split-thickness skin graft were applied.

Results: All wounds healed completely without any serious complications. Large defects up to 45 $\mathrm{mm}$ in diameter were successfully reconstructed using only PSS. Postoperative radiating folds were almost flattened after approximately 1-2 months.

Conclusion: PSS is simple, rapid, and relatively free from surgical design. Owing to the circumferential advancement of the surrounding tissue, PSS always results in a smaller scar than the initial lesion and less distortion of the body structures around the wound in the completely healed defect. If the operator can predict the process of healing and immediate radiating folds, PSS could be a favorable option for round skin defects in the head and neck.
\end{abstract}

Abbreviations: FTSG, full-thickness skin graft; PDS, polydioxanone; PSS, purse-string suture; RSTL, relaxed skin tension line; STSG, split-thickness skin graft.

Keywords: Face / Reconstructive surgical procedures / Scalp / Suture techniques

\section{INTRODUCTION}

The purse-string suture (PSS) is used for closure of round- or oval-shaped skin defects, which occur after excision of skin tumors or due to wounds caused by trauma. It makes complete closure of small to moderate defects easy. For large defects, PSS helps to reduce the defect size and makes it easier to apply other

Correspondence: Hyochun Park

Department of Plastic and Reconstructive Surgery, Daegu Fatima Hospital,

99 Ayang-ro, Dong-gu, Daegu 41199, Korea

E-mail: phc3900@hanmail.net

Received July 16, 2021 / Revised July 27, 2021 / Accepted August 12, 2021 covering methods, such as skin grafts or skin flaps [1-3].

PSS can be largely divided into subcuticular PSS [3-9], which does not expose the suture on the surface of the skin, and cuticular PSS [10,11], which exposes the suture on the surface of the skin. Each of the two PSS techniques can be applied with various modifications according to the wound's size, region, irregularity, and condition [7-18].

There are several studies on the surgical methods (i.e., undermining [1-3,7-9], suture material $[1,3-9,19])$, indications, postoperative management, and prediction of PSS results [4,7-10]. However, PSS is not widely used on the head and neck, particu- 
larly on the face, due to concerns about distortion of the adjacent areas or radiating folds that occur after surgery $[12,19]$. In this study, we examined the results of using the modified PSS technique on skin and soft tissue defects on the head and neck in terms of the surgical method and suture material.

\section{METHODS}

\section{Patient}

This retrospective study evaluated patients who underwent PSS for skin and soft tissue defects of the head and neck between 2016 and 2021. The included patients had round- or ovalshaped skin and soft tissue defects caused by the removal of facial masses or trauma. Among them, we selected patients in whom we expected cosmetic concerns to develop as an outcome of the traditional elliptical excision, as well as patients in whom it might be difficult to align the position of the scar parallel to the relaxed skin tension line (RSTL) or in whom, even if they could be aligned in parallel, the scar might be too long. The study conformed to the principles of the Declaration of Helsinki, and written consent was obtained from each patient for both the surgery and publication of the photographs of the results. The study was approved by the Institutional Review Board of Daegu Fatima Hospital (IRB No. DFE20ORIO090). The following data of the patients were analyzed: age, sex, date of operation, characteristics of the wound, diagnostic laboratory results, surgical intervention, and treatment data. Statistical analyses were performed using SPSS Subscription version 20.0 (IBM Corp., Armonk, NY, USA). To calculate the mean area of the affected area, descriptive statistics were performed on each category. Analysis of variance was used to compare the area of the defect and additional surgical interventions. Statistical significance was set at $p<0.05$.

\section{Surgical methods}

We modified the suture material and method of subcuticular PSS, which does not leave any suture marks on the surface of the skin. For round or oval defects caused by excision of tumors or peripheral debridement of traumatic defects, we first assessed the maximum possible central advancement tension using the pinch test and decided whether complete closure or additional repair, such as skin grafting, was required. Then, we performed dissection up to 2-5 $\mathrm{mm}$ in the subcutaneous layer along the periphery of the defect. The suture material was PDS II (polydioxanone; Ethicon Inc., Somerville, NJ, USA, 2-0 to 5-0), an absorbable monofilament. The thickness was chosen based on the size of the defect, tension required to approximate the skin's edge after dissection, and the thickness of the surrounding dermis.

The needle was inserted from the undermined subcutaneous tissue through half of the dermis emerging at the mid-dermal layer of the defect margin. The needle was inserted back at a distance of 3-5 $\mathrm{mm}$ in the mid-dermis. Subsequently, we let it emerge from a site $2-5 \mathrm{~mm}$ away in the same direction and continued the running suture in the mid-dermis margin. Once the needle reached the starting point, it was allowed to pass again from the mid-dermis layer to the subcutaneous layer, followed by gently pulling out the suture and tying it. While conventional subcuticular PSS has a knot in the mid-dermis, which is often exposed to the surface of the skin, we placed the knot under the skin so that it was not exposed to the surface of the skin (Fig. 1A).

In general, the affected area with a small size or sufficient re-
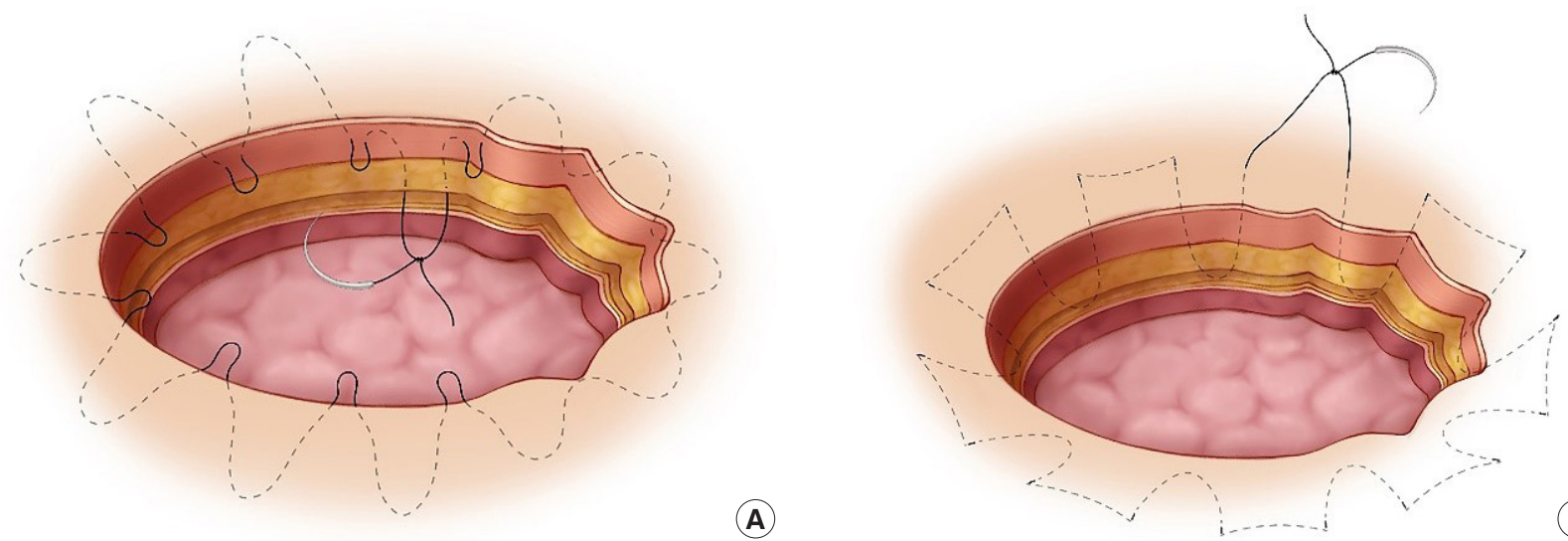

Fig. 1. Purse-string suture (PSS) method. (A) Modified subcuticular PSS using polydioxanone. Minimal undermining of the subcutaneous layer was done. (B) Modified cuticular PSS using Surgipro. Cuticular PSS was not used alone, and if the defect was large enough for double PSS, it was performed before subcuticular PSS. 
dundancy was bitten with a width of $3 \mathrm{~mm}$ using a 4-0 or 5-0 PDS, followed by a running suture with an interval of $2 \mathrm{~mm}$. At sites that required a slightly stronger traction force, we used 2-0 or 3-0 PDS and increased the bite and interval by 1 to $2 \mathrm{~mm}$ to reduce the interference with the circulation.

After complete closure via PSS, we applied several skin sutures using 6-0 Surgipro (polypropylene; Covidien, Mansfield, MA, USA) for good skin edge coaptation (Fig. 2). In incomplete closure cases, we applied several interrupted subdermal sutures to make side-to-side advancement for complete closure. In cases of large or high-tension defects, which required more traction, we applied an additional modified cuticular PSS. At a distance of $0.5-1 \mathrm{~cm}$ from the defect margin, we first applied modified cuticular PSS using Surgipro, a non-absorbable suture material, to reduce the size of the defect. An additional subcuticular PSS was then implemented (double PSS).

Here, we performed the modified cuticular PSS according to the method described by Weisberg and Greenbaum [9] in which stitch marks were minimized via continuous buried sutures by inserting the needle back to the same epidermal site after it exits a site (Fig. 1B). When the defect was too large to be completely covered even by double PSS, we performed conventional PSS to reduce the size of the defect and applied a splitthickness skin graft (STSG).

After the wound had been closed, we applied a dressing using an antibiotic ointment and foam. In cases with STSG, we applied a dressing in the same manner as for STSG management. Most surgeries were performed under local anesthesia. However, patients that required STSG or other accompanying surgeries elsewhere were administered general anesthesia. All patients who had undergone PSS under local anesthesia were discharged on the day of the surgery or the day after admission.
We performed follow-up on the 1st and 5th day after surgery, in the 1st, 2nd, and 3rd month, to confirm the ongoing flattening of the radiating fold. We did not remove the PDS suture. The 6-0 Surgipro skin suture was removed 5-8 days after the surgery.

\section{RESULTS}

We performed PSS at 45 sites in 39 patients (Table 1), consisting of defects due to trauma ( 1 site), benign skin tumor excision (16 sites), and wide excision of malignant or premalignant skin cancer lesions (28 sites). The type of excised benign skin tumors included seborrheic keratosis, keratoacanthoma, epidermal cyst, and intradermal nevus. The type of excised malignant or premalignant skin cancer lesions included actinic keratosis, Bowen's disease, basal cell carcinoma, squamous cell carcinoma, and sarcomatoid squamous cell carcinoma. The age of the patients ranged from 4 to 90 years (mean \pm standard deviation, $71.38 \pm 19.56$ years; 16 male and 23 female). The size of the defects ranged from $5 \times 5 \mathrm{~mm}$ to $70 \times 90 \mathrm{~mm}$. There were 44 wounds with a round or oval shape, whereas one wound caused by trauma had an irregular shape (Fig. 3); for the two wounds with sizes $90 \times 70 \mathrm{~mm}$ and $83 \times 65 \mathrm{~mm}$ were reconstructed by applying STSG after PSS; for the three wounds with sizes $28 \times 25 \mathrm{~mm}, 25 \times 23 \mathrm{~mm}$, and $25 \times 22 \mathrm{~mm}$, we performed double PSS; for the seven wounds with sizes ranging from $15 \times 14$ $\mathrm{mm}$ to $45 \times 40 \mathrm{~mm}$, for those with leftover small defects even after undergoing PSS, we applied buried sutures in the dermis and subcutaneous layer for side-to-side advancement. For the remaining 33 wounds whose sizes ranged from $5 \times 5$ to $31 \times 24$ $\mathrm{mm}$, we performed modified PSS.

The average width of the defects was $20.31 \pm 14.74 \mathrm{~mm}$, and
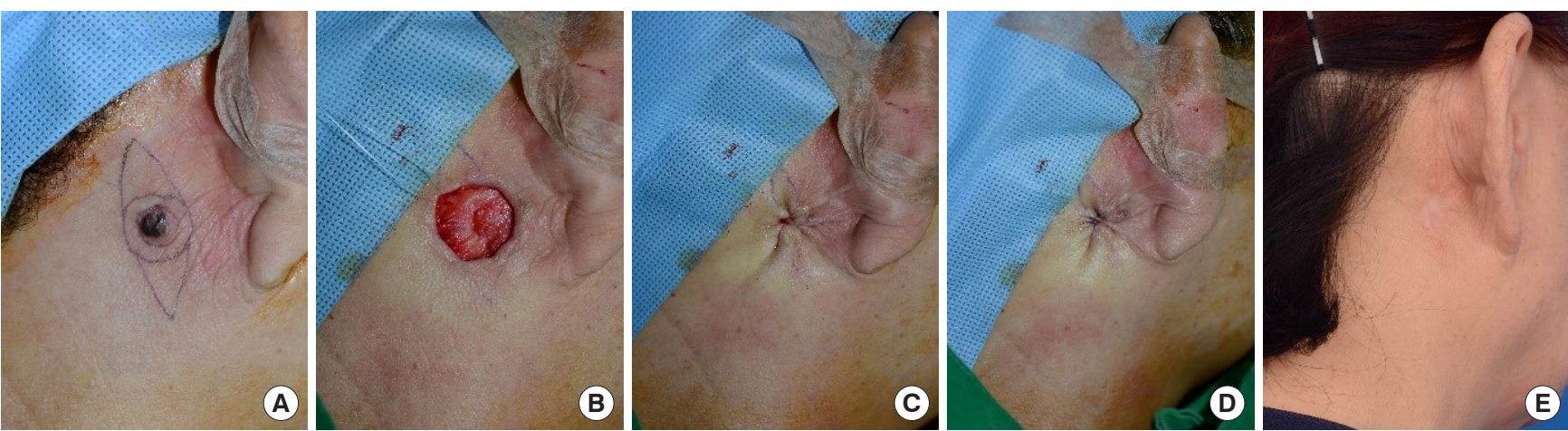

Fig. 2. A 71-year-old woman with basal cell carcinoma located in the right postauricular area. A wide excision was planned, and although a surgical design for elliptical excision was made, the purse-string suture (PSS) method was used to reduce the size of the scar. (A) The size of the basal cell carcinoma was $0.7 \times 0.5 \mathrm{~cm}$, and the safety margin was $3 \mathrm{~mm}$. (B) The size of the defect was measured as $1.3 \times 1.1 \mathrm{~cm}$, and $4-0$ polydioxanone was used for modified subcuticular PSS. (C) The suture was pulled for complete closure. (D) The skin was sutured using 6-0 Surgipro. (E) A postoperative photo after 9 months showing that the concentric skin folds and distortion had resolved. 
Table 1. Patient characteristics

\begin{tabular}{|c|c|}
\hline Characteristic & Value \\
\hline No. of patients (sites) & $39(45)$ \\
\hline \multicolumn{2}{|l|}{ Sex } \\
\hline Male & 16 \\
\hline Female & 23 \\
\hline Age at operation (yr), mean $\pm S D$ & $71.38 \pm 19.56$ \\
\hline Reconstruction site & 45 \\
\hline Temporal area & 7 \\
\hline Cheek & 21 \\
\hline Nose & 6 \\
\hline Preauricular area & 2 \\
\hline Chin and mandibular area & 3 \\
\hline Scalp & 1 \\
\hline Postauricular area & 5 \\
\hline \multicolumn{2}{|l|}{ Pathology } \\
\hline Trauma & 1 \\
\hline Benign tumor & 16 \\
\hline Malignant or premalignant skin cancer & 28 \\
\hline \multicolumn{2}{|l|}{ Character of the defect, mean \pm SD } \\
\hline Width of the defect (mm) & $20.31 \pm 14.74$ \\
\hline Length of the defect (mm) & $20.16 \pm 16.46$ \\
\hline Area of the defect $\left(\mathrm{mm}^{2}\right)^{\mathrm{a})}$ & $503.47 \pm 1,070.11$ \\
\hline Defect due to trauma $\left(\mathrm{mm}^{2}\right)$ & 706.86 \\
\hline Defect due to benign skin tumor $\left(\mathrm{mm}^{2}\right)$ & $175.14 \pm 135.70$ \\
\hline $\begin{array}{l}\text { Defect due to malignant or premalignant skin cancer } \\
\left(\mathrm{mm}^{2}\right)\end{array}$ & $683.83 \pm 1,325.43$ \\
\hline \multicolumn{2}{|l|}{ Reconstruction method } \\
\hline Modified subcuticular PSS & 33 \\
\hline Additional side-to-side advancement suture & 7 \\
\hline Double PSS & 3 \\
\hline Additional STSG & 2 \\
\hline
\end{tabular}

PSS, purse-string suture; STSG, split-thickness skin graft. ${ }^{a}$ Width $/ 2 \times$ length $/ 2 \times \pi$. the average length was $20.16 \pm 16.46 \mathrm{~mm}$. The defect area was calculated using the formula for the area of an ellipse (width $/ 2 \times$ length $/ 2 \times \pi$ ). The average area was $503.47 \pm 1,070.11$ $\mathrm{mm}^{2}$. This is because two wounds reconstructed using PSS with STSG were considerably larger than the other wounds (Table 2). Excluding these two wounds, the average area was $282.96 \pm 274.48 \mathrm{~mm}^{2}$. The mean area of the defects from which benign skin tumors were excised was $175.14 \pm 135.70 \mathrm{~mm}^{2}$. The mean area of the defects from which malignant or premalignant skin lesions were excised was $683.83 \pm 1,325.43 \mathrm{~mm}^{2}$. Excluding the two wounds reconstructed using PSS with STSG, the mean area was $333.01 \pm 313.51 \mathrm{~mm}^{2}$. The mean of the affected areas was $5,244.50 \pm 419.29 \mathrm{~mm}^{2}$ in patients in whom a STSG was applied, $477.78 \pm 63.12 \mathrm{~mm}^{2}$ in those in whom double PSS was applied, $694.52 \pm 416.21 \mathrm{~mm}^{2}$ in those in whom a PSS with additional side-to-side advancement sutures was applied, and $177.95 \pm 119.05 \mathrm{~mm}^{2}$ in those in whom only a modified PSS was applied (Table 2). There were partial correlations between the affected area and the application of additional surgical interventions for reconstruction $(p<0.05)$. There was a statistically significant difference in the area of the affected area between the patients who underwent only PSS and those who underwent double PSS. There was also a statistically significant difference between the patients who underwent PSS with advancement suture and those who underwent with STSG $(p<0.05)$ (Table 3). However, there was no statistically significant difference between the other different surgical methods.

In all affected areas and patients, there were no early complications such as infection, hematoma, and seroma or severe complications such as dehiscence and flap necrosis. There were four cases of marginal wound contusions. In such cases, we partially removed Surgipro skin suture to improve the circula-
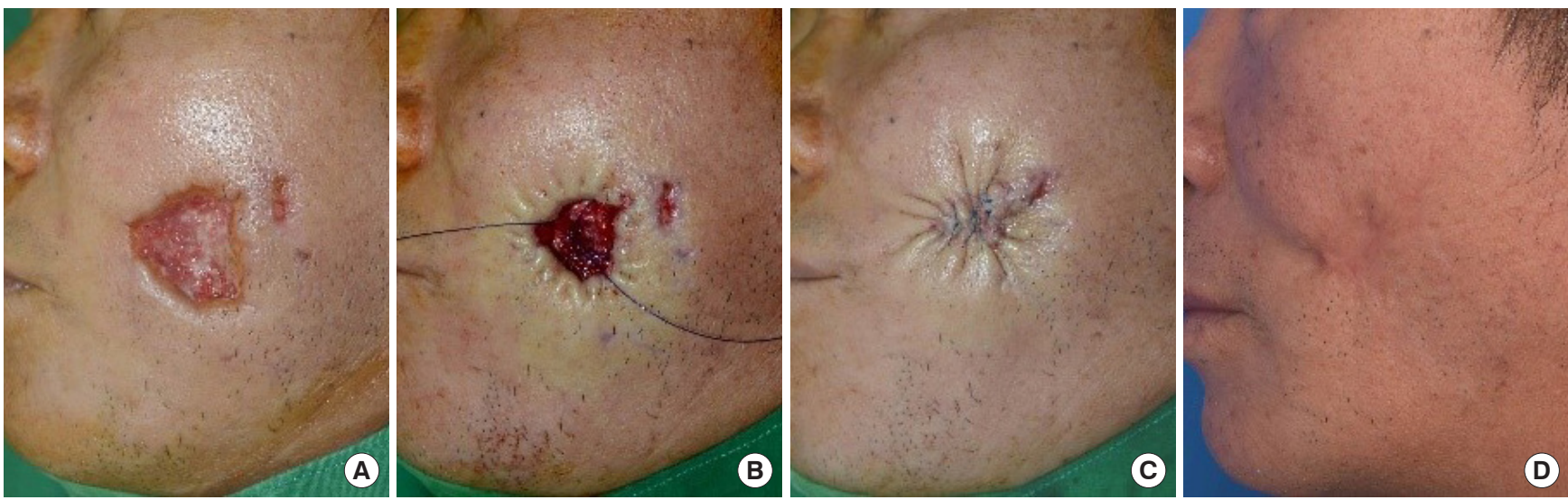

Fig. 3. A 52-year-old man with a skin and soft tissue defect due to a dog bite on the left cheek. (A) The size of the defect was $3.0 \times 3.0 \mathrm{~cm}$. (B) A photograph was taken before tying the purse-string suture. (C) A subdermal suture was inserted using 5-0 polydioxanone for side-to-side advancement, and 6-0 Surgipro was used for complete closure. (D) A photograph was taken 10 months postoperatively. 
Table 2. The relationship between the affected wound area and the surgical method

\begin{tabular}{llccc}
\hline Variable & \multicolumn{1}{c}{ Operations } & Mean \pm SD $\left(\mathrm{mm}^{2}\right)$ & F-value & $p$-value \\
\hline Area of the affected area & Modified PSS only & $177.95 \pm 119.05$ & 397.03 & $0.000^{\mathrm{a})}$ \\
& PSS with Side-to-side advancement suture & $694.52 \pm 416.21$ & & \\
& Double PSS & $477.78 \pm 63.12$ & \\
& PSS with STSG & $5,244.50 \pm 419.29$ & \\
\hline
\end{tabular}

PSS, purse-string suture; STSG, split-thickness skin graft.

a)Statistically significant, $p<0.05$.

Table 3. Post hoc test results on the relationship between the affected wound area and the surgical method

\begin{tabular}{|c|c|c|c|}
\hline Operations & & $p$-value & Result \\
\hline \multirow[t]{3}{*}{ Modified PSS only (a) } & PSS with Side-to-side advancement suture (b) & 0.077 & (a) $<$ (c), (b) $<$ (d) \\
\hline & Double PSS (c) & $0.014^{\mathrm{a})}$ & (Dunnett T3) \\
\hline & PSS with STSG (d) & 0.076 & \\
\hline \multirow[t]{2}{*}{ PSS with side-to-side advancement suture (b) } & Double PSS (c) & 0.702 & \\
\hline & PSS with STSG (d) & $0.031^{\text {a) }}$ & \\
\hline Double PSS (c) & PSS with STSG (d) & 0.077 & \\
\hline
\end{tabular}

PSS, purse-string suture; STSG, split-thickness skin graft.

a) Statistically significant, $p<0.05$.

tion of the wound edge. All of wounds healed with secondary intention within 1 month after surgery. Radiating skin folds significantly decreased within 4 weeks in most patients. If the defect was located close to the nose or eyelids, distortion of the nose and strained eyefold appeared immediately after surgery. However, these distortions disappeared completely within 2 months as the radiating folds disappeared. In all patients, the suture length was equal to or smaller than the initial lesion width. The scar length after wound healing also did not differ from the suture length immediately after the operation.

\section{DISCUSSION}

By gathering the skin around $360^{\circ}$, PSS achieves maximum and uniform advancement of the defect, enabling wound sealing of the smallest sizes [1-3]. Moreover, it leaves the smallest possible scar with minimal distortion of the surrounding structures $[3,7,9,18]$. Since skin resections as small as $1 \mathrm{~mm}$ on the face can lead to unfavorable structural changes [20], PSS has cosmetic advantages over other wound closure methods as it has a smaller scar width than the original wound and looks natural as it aligns with RSTL over time [1,3].

PSS is worth including in a wound repair plan as it allows patients to return to daily life immediately after surgery [11]. Additionally, it is easy to apply in patients with a poor general condition who are ineligible for other types of large reconstructions $[2,10]$. It enhances hemostasis at the wound's edge $[10,21]$ and wound healing [19,21], thereby being feasible in patients with unstable hemodynamics or those receiving anticoagulants.
The advantages of PSS arise from its active utilization of the molding properties of the skin. Gibson and Kenedi [22] reported the viscoelastic properties of the skin, which involve mechanical creep and stress relaxation. Mechanical creep occurs when a piece of skin is stretched by a constant force; the skin will continue to extend depending on the force involved. Stress relaxation, a corollary of creep, occurs when a piece of skin is stretched for a given distance, and the distance is held constant while the force required to keep it stretched gradually decreases [23]. PSS is a method of primary closure of defects that actively utilizes the interaction between mechanical creep and stress relaxation.

\section{Suture materials}

To properly utilize this interaction, it is important to select an appropriate suture material.

In many studies, nonabsorbable suture materials (nylon and Prolene) $[1,2,4,6,8,9,19]$ and possibly the thickest threads (2-0 or thicker) [1,2,4,7-10,19] were used for PSS. However, some studies implemented PSS with a thread of a small diameter [2$4,6,7,9]$ or absorbable suture material (Monocryl; Ethicon Inc., Somerville, NJ, USA) $[5,7,9,10]$. It has been reported that Monocryl loses $60 \%-70 \%$ of its original tension within the first 2 weeks, and $100 \%$ within 3-4 weeks, increasing the risk of dehiscence [24,25].

Nonabsorbable suture materials require removal of sutures. In case of early suture removal, there is a chance that wound dehiscence may occur. If the suture removal is postponed to prevent wound dehiscence, stitch marks may occur, which are cos- 
metically undesirable. In our practice, we used PDS as it is an absorbable material. A $4-0$ or thinner PDS retains $60 \%$ of its original tension for up to 2 weeks and $40 \%$ for up to 4 weeks. A thicker PDS retains $80 \%$ of its original tension for up to 2 weeks and $70 \%$ for up to 4 weeks [26]. PDS is a monofilament that sufficiently reduces the possibility of a foreign body reaction, allows for adequate stress relaxation, and gives an appropriate and predictable degree of tension reduction to generate an acceptable stretch in the skin.

\section{Undermining}

Various studies have been conducted on wound edge undermining. Several studies have reported that not performing undermining enhances wound repair by maximizing the vascularity at the edge of the surgical wound, prevents distortion of adjacent structures, and causes maturation of the final scar along the natural line of the RSTL $[1,3,9]$. Conversely, several investigators $[2,7,8]$ have claimed that undermining of several millimeters [27] to $5 \mathrm{~cm}$ [2] enhances wound closure and minimizes the perimeter of rippling $[8,27]$.

If undermining is not performed, the stronger the tension, greater the inversion of the suture margin. If too much undermining is performed, the flattening of rippling is delayed, or the scar is not parallel to the RSTL. Therefore, in our practice, we performed $1-5 \mathrm{~mm}$ of undermining in all defects. Undermining was performed primarily in the subcutaneous layer. However, if deep wounds were observed, PSS was performed in the suprafascial layer. This placed the suture knot in the subcutaneous layer and prevented it from being exposed to the skin's surface, secured adequate vascularity, allowed for margin eversion to enhance sealing, and let the approximation be as parallel to the RSTL as possible. As a result, large defects of up to $45 \times 40$ $\mathrm{mm}$ could be reconstructed with only PSS, and without STSG.

Here, we performed PSS with minimal undermining (1-2 $\mathrm{mm}$ ) on wounds around structures such as the eyelids, the eyebrows, and the nose, which are sensitive to distortion $[28,29]$. While distortions occurred immediately after the operation, they disappeared as the radiating fold improved, with restoration of the original shapes (Fig. 4).

\section{Radiating fold}

Radiating skin folds, which occur immediately after surgery,
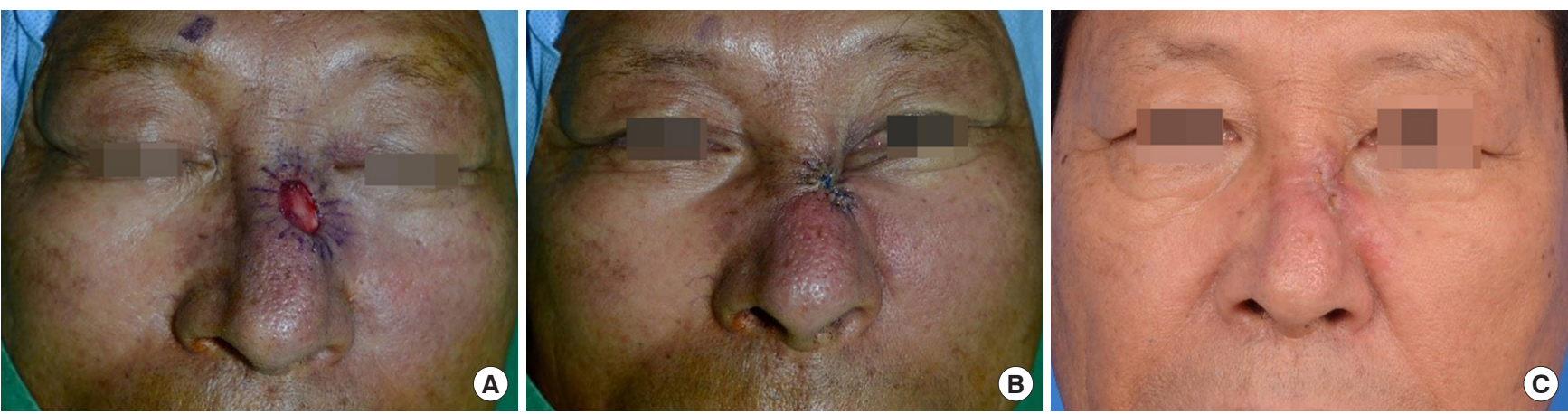

Fig. 4. A 66-year-old man with basal cell carcinoma in the dorsum of the nose. (A) The size of the defect was $1.8 \times 1.7 \mathrm{~cm}$. (B) Radiating skin folds and distortion near the left medial canthus can be observed in the immediate postoperative photograph. (C) A photograph was taken 2 weeks postoperatively. The concentric skin folds and distortion appear to be resolved.
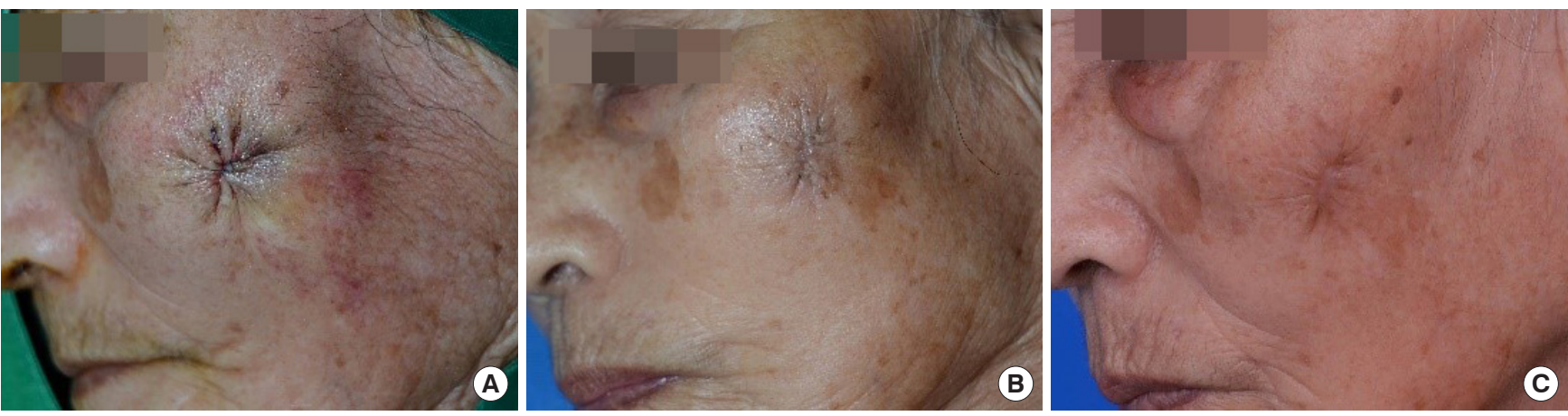

Fig. 5. An 82-year-old woman with keratoacanthoma in the left cheek. (A) The size of the defect was $1.4 \times 1.4 \mathrm{~cm}$. Radial folds are visible in the immediate postoperative photograph. (B) One month after the surgery, the wound was nearly healed. Although the radial fold improved, some distortion still remained. (C) Four months after the surgery, the scar shows some improvement, but it took longer for the radial fold to disappear. 
Table 4. Additional intervention with PSS according to defect area

\begin{tabular}{|c|c|c|c|c|c|c|c|c|c|}
\hline No. & Age (yr) & Sex & Type & Area $\left(\mathrm{mm}^{2}\right)$ & Width (mm) & Length (mm) & Additional intervention & Location & Suture materials \\
\hline 1 & 52 & M & Trauma & 706.86 & 30 & 30 & Advancement suture & Cheek & 1-0 PDS, 4-0 Surgipro \\
\hline 2 & 12 & M & Benign & 50.27 & 8 & 8 & & Chin & 4-0 PDS, 6-0 Surgipro \\
\hline 3 & 21 & $\mathrm{~F}$ & Benign & 78.54 & 10 & 10 & & Scalp & 4-0 PDS, 6-0 Surgipro \\
\hline 4 & 52 & M & Benign & 78.54 & 10 & 10 & & Postauricular area & 5-0 PDS, 6-0 Surgipro \\
\hline 5 & 75 & M & Benign & 78.54 & 10 & 10 & & Cheek & 5-0 PDS, 6-0 Surgipro \\
\hline 6 & 76 & $F$ & Benign & 78.54 & 10 & 10 & & Postauricular area & 5-0 PDS, 6-0 Surgipro \\
\hline 7 & 75 & $\mathrm{~F}$ & Benign & 95.03 & 11 & 11 & & Mandibular angle & 4-0 PDS, 6-0 Surgipro \\
\hline 8 & 74 & M & Benign & 113.10 & 12 & 12 & & Temporal area & 4-0 PDS, 6-0 Surgipro \\
\hline 9 & 4 & M & Benign & 120.95 & 11 & 14 & & Cheek & 4-0 PDS, 7-0 Surgipro \\
\hline 10 & 54 & M & Benign & 142.94 & 13 & 14 & & Temporal area & 4-0 PDS, 6-0 Surgipro \\
\hline 11 & 82 & $\mathrm{~F}$ & Benign & 153.94 & 14 & 14 & & Cheek & 4-0 PDS, 6-0 Surgipro \\
\hline 12 & 85 & $\mathrm{~F}$ & Benign & 176.71 & 15 & 15 & & Temporal area & 4-0 PDS, 6-0 Surgipro \\
\hline 13 & 86 & $\mathrm{~F}$ & Benign & 213.63 & 17 & 16 & & Cheek & 4-0 PDS, 6-0 Surgipro \\
\hline 14 & 83 & $\mathrm{~F}$ & Benign & 314.16 & 20 & 20 & & Cheek & 4-0 PDS, 6-0 Surgipro \\
\hline 15 & 85 & $\mathrm{~F}$ & Benign & 392.70 & 20 & 25 & & Cheek & 4-0 PDS, 6-0 Surgipro \\
\hline 16 & 57 & M & Benign & 164.93 & 15 & 14 & Advancement suture & Cheek & 4-0 PDS, 4-0 Surgipro \\
\hline 17 & 48 & M & Benign & 549.78 & 28 & 25 & Double PSS & Postauricular area & 2-0 PDS, 3-0 nylon \\
\hline 18 & 88 & $\mathrm{~F}$ & Malignant & 19.63 & 5 & 5 & & Nose & 4-0 PDS, 6-0 Surgipro \\
\hline 19 & 68 & M & Malignant & 49.48 & 7 & 9 & & Nose & 4-0 PDS, 6-0 Surgipro \\
\hline 20 & 68 & M & Malignant & 50.27 & 8 & 8 & & Nose & 5-0 PDS, 6-0 Surgipro \\
\hline 21 & 81 & $\mathrm{~F}$ & Malignant & 113.10 & 12 & 12 & & Preauricular area & 4-0 PDS, 6-0 Surgipro \\
\hline 22 & 70 & $\mathrm{~F}$ & Malignant & 131.95 & 14 & 12 & & Postauricular area & 4-0 PDS, 6-0 Surgipro \\
\hline 23 & 84 & $\mathrm{~F}$ & Malignant & 131.95 & 14 & 12 & & Mandibular angle & 5-0 PDS, 6-0 Surgipro \\
\hline 24 & 77 & $\mathrm{~F}$ & Premalignant & 142.94 & 14 & 13 & & Cheek & 4-0 PDS, 6-0 Surgipro \\
\hline 25 & 63 & $\mathrm{~F}$ & Premalignant & 153.94 & 14 & 14 & & Nose & 4-0 PDS, 6-0 Surgipro \\
\hline 26 & 87 & $\mathrm{~F}$ & Malignant & 173.57 & 17 & 13 & & Cheek & 4-0 PDS, 6-0 Surgipro \\
\hline 27 & 87 & $\mathrm{~F}$ & Malignant & 176.71 & 15 & 15 & & Cheek & 4-0 PDS, 6-0 Surgipro \\
\hline 28 & 66 & M & Malignant & 201.06 & 16 & 16 & & Nose & 4-0 PDS, 6-0 Surgipro \\
\hline 29 & 83 & $\mathrm{~F}$ & Malignant & 201.06 & 16 & 16 & & Preauricular area & 4-0 PDS, 6-0 Surgipro \\
\hline 30 & 86 & $\mathrm{~F}$ & Malignant & 201.06 & 16 & 16 & & Cheek & 4-0 PDS, 6-0 Surgipro \\
\hline 31 & 72 & $\mathrm{~F}$ & Malignant & 212.06 & 18 & 15 & & Cheek & 3-0 PDS, 6-0 Surgipro \\
\hline 32 & 66 & M & Malignant & 240.33 & 18 & 17 & & Nose & 3-0 PDS, 6-0 Surgipro \\
\hline 33 & 83 & $\mathrm{~F}$ & Malignant & 298.45 & 20 & 19 & & Cheek & 4-0 PDS, 6-0 Surgipro \\
\hline 34 & 77 & M & Premalignant & 329.87 & 20 & 21 & & Temporal area & 4-0 PDS, 6-0 Surgipro \\
\hline 35 & 86 & M & Malignant & 373.06 & 25 & 19 & & Cheek & 3-0 PDS, 6-0 Surgipro \\
\hline 36 & 79 & $\mathrm{~F}$ & Malignant & 584.34 & 31 & 24 & & Temporal area & 3-0 PDS, 6-0 Surgipro \\
\hline 37 & 87 & $\mathrm{~F}$ & Malignant & 346.36 & 21 & 21 & Advancement suture & Cheek & 3-0, 4-0 PDS, 6-0 Surgipro \\
\hline 38 & 80 & $\mathrm{~F}$ & Malignant & 490.09 & 26 & 24 & Advancement suture & Cheek & 2-0, 3-0 PDS, 5-0 Surgipro \\
\hline 39 & 88 & $\mathrm{~F}$ & Malignant & 777.54 & 30 & 33 & Advancement suture & Cheek & 3-0, 4-0 PDS, 6-0 Surgipro \\
\hline 40 & 90 & $F$ & Malignant & 962.11 & 35 & 35 & Advancement suture & Cheek & 3-0 PDS, 6-0 Surgipro \\
\hline 41 & 84 & $\mathrm{~F}$ & Malignant & $1,413.72$ & 45 & 40 & Advancement suture & Cheek & $\begin{array}{l}\text { 4-0 PDS, 5-0 Surgipro } \\
\text { 5-0 PDS, 6-0 Surgipro }\end{array}$ \\
\hline 42 & 80 & $\mathrm{~F}$ & Malignant & 431.97 & 25 & 22 & Double PSS & Temporal area & 4-0 PDS, 5-0 Surgipro \\
\hline 43 & 55 & M & Malignant & 451.60 & 25 & 23 & Double PSS & Cheek & 3-0 PDS, 5-0 Surgipro \\
\hline 44 & 80 & $\mathrm{~F}$ & Malignant & $4,948.01$ & 70 & 90 & STSG & Temporal area & 2-0 PDS, 4-0 Surgipro, 4-0 black silk \\
\hline 45 & 76 & M & Malignant & $5,540.98$ & 83 & 85 & STSG & Postauricular area & 2-0 PDS, 4-0 Surgipro, 4-0 black silk \\
\hline
\end{tabular}

M, male; F, female; PSS, purse-string suture; STSG, split-thickness skin graft; PDS, polydioxanone. 

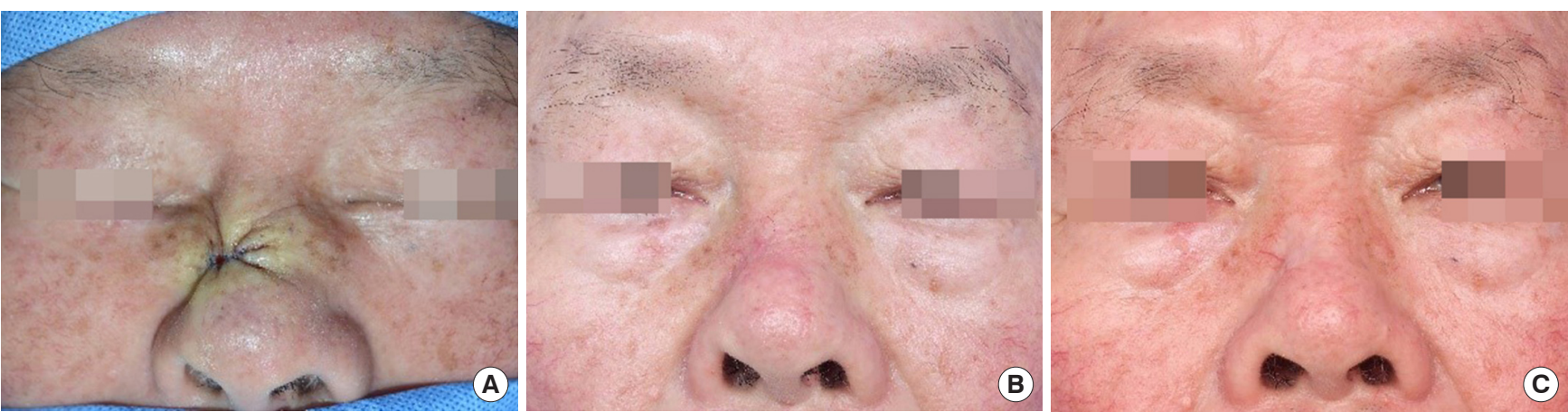

Fig. 6. A 66-year-old man with basal cell carcinoma in the dorsum of the nose. (A) The size of the defect was $1.6 \times 1.6 \mathrm{~cm}$. Radial folds and a distorted nose are visible in the immediate postoperative photograph. (B) One month after the surgery, the wound was almost healed, and the radial folds were almost resolved, but the distortion of the nose persisted. (C) Four months after the surgery, the nose distortion was resolved.

discourage PSS application. Therefore, it is necessary, before surgery, to provide the patients and caregivers with sufficient information about the folds and progressive sequelae according to the wound changes [12]. PSS is generally known to be a more applicable technique among the elderly considering the skin's laxity $[4,7,9,10,19]$. However, in our practice, although direct closure using PSS was easier to perform in elderly patients with more skin laxity and greater redundancy, radiating folds took longer to disappear. In elderly patients, it takes almost 2-6 months for complete disappearance, especially in the cheeks (Fig. 5). Radiating folds, in contrast, tended to fade faster in younger patients with thicker skin and greater elasticity. Six months after surgery, radiating skin folds disappeared in all patients.

\section{Application of additional interventions}

To determine whether PSS only or additional interventions are required for complete closure, assessing the advancement tension is important. We performed the pinch test before and after tumor resection; if the defect site or both edges of the defect can be closed with low tension, PSS alone may be sufficient. However, if the tension required to cover the defect is high, an advancement suture or double PSS is required. Generally, double PSS has more traction than PSS with an advancement suture, but whether an advancement suture is sufficient or double PSS is necessary depends on the size, area, skin elasticity, thickness, and depth of the defect. Defect sizes of $45 \times 40 \mathrm{~mm}$ and $35 \times 35$ $\mathrm{mm}$ in the cheek area of the elderly were closed with an advancement suture, but a defect size of $25 \times 23 \mathrm{~mm}$ in the cheek area of a middle-aged patient had to be reconstructed with double PSS. In the temporal region of two elderly patients of the same age, a defect size of $31 \times 24 \mathrm{~mm}$ was completely closed using PSS only, but that of $25 \times 22 \mathrm{~mm}$ had to be reconstructed with double PSS (Table 4).
Advancement sutures were applied when defect less than 5 $\mathrm{mm}$ in diameter remained after PSS. Double PSS was applied when more traction was required. In our experience, PSS alone can be applied to a defect size of $2 \mathrm{~cm}$ or less regardless of the site. Even for a defect with a size exceeding $2 \mathrm{~cm}$ in the cheek and temporal regions of the face, PSS was actively applied. If the defect size in the area adjacent to the nose or medial epicanthus exceeded $2 \mathrm{~cm}$, complete closure was expected to be difficult, even with an advancement suture or double PSS. In this area, distortion occurs in the adjacent area immediately after surgery. However, the radiating folds disappear in this area faster than in other areas (Fig. 6). In the preauricular and postauricular areas, if the size of the defect exceeded $2 \mathrm{~cm}$, double PSS was applied, but no advancement suture was applied to this area in any patient; therefore, it is difficult to clearly distinguish this. In the scalp region, PSS was used only for defects less than $1 \mathrm{~cm}$ in size in the occipital regions with some elasticity. Regardless of the site, if the area was too large to close even with double PSS, STSG was performed along with PSS. As the defect was too large for a full-thickness skin graft (FTSG), we applied STSG. If small defects remain after double PSS, FTSG can be considered, but there was no such case in our study.

The PSS technique described in this paper was modified by using an absorbable suture material and minimal undermining, placing the suture knot in the subcutaneous layer. Therefore, it can simplify the management, improve cosmetic results, and be applied to large defects in the entire craniofacial region. Ideal reconstruction of the face has no stenosis or distortion after reconstruction and good agreement of the skin tone [30]. The application of PSS is more convenient than local flaps or FTSG, which are widely used for craniofacial reconstruction, and does not require the skin incisions needed for the use of donor sites or flap designs. Above all, the scar length after complete healing is small, and if applied well, there are fewer contracture areas 
and unnatural skin tones compared with other techniques, resulting in satisfactory cosmetic results.

If more data on the prognosis of wound healing and radiation folds are accumulated, it can become a more active, simple, and convenient option for facial reconstruction.

\section{NOTES}

\section{Conflict of interest}

No potential conflict of interest relevant to this article was reported.

\section{Ethical approval}

The study was approved by the Institutional Review Board of Daegu Fatima Hospital (IRB No. DFE20ORIO090) and performed in accordance with the principles of the Declaration of Helsinki. Written informed consent was obtained.

\section{Patient consent}

The patients provided written informed consent for the publication and the use of their images.

\section{ORCID}

Hyochun Park

Yunjae Lee

Hyeonjung Yeo

Hannara Park

$$
\begin{aligned}
& \text { https://orcid.org/0000-0001-6019-8002 } \\
& \text { https://orcid.org/0000-0002-0897-3216 } \\
& \text { https://orcid.org/0000-0001-5705-7380 } \\
& \text { https://orcid.org/0000-0003-4158-0489 }
\end{aligned}
$$

\section{Author contribution}

Conceptualization: HP, YL, HY, Hannara Park. Data curation, formal analysis, methodology: HP, YL, HY, Hannara Park. Project administration, visualization, investigation: HP, YL, HY, Hannara Park. Resources, software, supervision, validation: HP, YL, HY, Hannara Park. Writing - original draft: HP, YL, HY, Hannara Park. Writing - review \& editing: HP, YL, HY, Hannara Park.

\section{REFERENCES}

1. Tremolada C, Blandini D, Beretta M, Mascetti M. The "round block" purse-string suture: a simple method to close skin defects with minimal scarring. Plast Reconstr Surg 1997;100:12631.

2. Brady JG, Grande DJ, Katz AE. The purse-string suture in facial reconstruction. J Dermatol Surg Oncol 1992;18:812-6.

3. Mulliken JB, Rogers GF, Marler JJ. Circular excision of hemangioma and purse-string closure: the smallest possible scar. Plast
Reconstr Surg 2002;109:1544-55.

4. Mather MK, Harrington AC, Montemarano A, Farley M. Surgical pearl: purse string suture in the management of poorly delineated melanomas. J Am Acad Dermatol 1998;38:99-101.

5. Yuen JC. Versatility of the subcuticular purse-string suture in wound closure. Plast Reconstr Surg 1996;98:1302-5.

6. Peled IJ, Zagher U, Wexler MR. Purse-string suture for reduction and closure of skin defects. Ann Plast Surg 1985;14:465-9.

7. Romiti R, Randle HW. Complete closure by purse-string suture after Mohs micrographic surgery on thin, sun-damaged skin. Dermatol Surg 2002;28:1070-2.

8. Ciatti S, Greenbaum SS. Modified purse-string closure for reconstruction of moderate/large surgical defects of the face. Dermatol Surg 1999;25:215-20.

9. Weisberg NK, Greenbaum SS. Revisiting the purse-string closure: some new methods and modifications. Dermatol Surg 2003;29:672-6.

10. Cohen PR, Martinelli PT, Schulze KE, Nelson BR. The cuticular purse string suture: a modified purse string suture for the partial closure of round postoperative wounds. Int J Dermatol 2007;46:746-53.

11. Cohen PR, Martinelli PT, Schulze KE, Nelson BR. The pursestring suture revisited: a useful technique for the closure of cutaneous surgical wounds. Int J Dermatol 2007;46:341-7.

12. Kilic A, Kilic A. "Round-block" purse-string suture on skin graft. Plast Reconstr Surg 2001;108:1456-7.

13. Marconi F. Reconstruction of the umbilicus: a simple technique. Plast Reconstr Surg 1995;95:1115-7.

14. Marconi F. The dermal pursestring suture: a new technique for a short inframammary scar in reduction mammaplasty and dermal mastopexy. Ann Plast Surg 1989;22:484-94.

15. Persichetti P, Berloco M, Casadei RM, Marangi GF, Di Lella F, Nobili AM. Gynecomastia and the complete circumareolar approach in the surgical management of skin redundancy. Plast Reconstr Surg 2001;107:948-54.

16. Toth BA, Daane SP. Purse-string mastectomy with immediate prosthetic reconstruction: an improved skin-sparing technique for small breasts. Plast Reconstr Surg 2003;111:2333-7.

17. Matsumine H, Takeuchi M, Mori S, Sakurai H. A pentagram suture technique for closing tumor resection sites in the face. Plast Reconstr Surg Glob Open 2015;3:e499.

18. Harrington AC, Montemarano A, Welch M, Farley M. Variations of the pursestring suture in skin cancer reconstruction. Dermatol Surg 1999;25:277-81.

19. Kilic A. Presutured purse-string suture and second pursestring suture for both reduction and closure of skin defects. Plast Reconstr Surg 2002;109:1758-60.

20. Kim ES, Yang CE, Chung YK. Does reduction of the oncologic 
safety margin for facial basal cell carcinoma result in higher recurrence rates? Arch Craniofac Surg 2021;22:135-40.

21. Lantieri LA, Martin-Garcia N, Wechsler J, Mitrofanoff M, Raulo Y, Baruch JP. Vascular endothelial growth factor expression in expanded tissue: a possible mechanism of angiogenesis in tissue expansion. Plast Reconstr Surg 1998;101:392-8.

22. Gibson T, Kenedi RM. Biomechanical properties of skin. Surg Clin North Am 1967;47:279-94.

23. Lee JW, Park SH, Lee SJ, Kim SH, Jeong HS, Suh IS. New economical and simple device for intraoperative expansion on small and medium sized soft tissue defects. Arch Craniofac Surg 2018;19:235-9.

24. Randle HW. Re.: Cosmetic surgery is not plastic surgery. Dermatol Surg 2004;30:237.

25. Weisberg NK, Greenbaum SS. Re.: Cosmetic surgery is not plastic surgery. Dermatol Surg 2004;30:237.

26. Dunn DL, Phillips J. The suture. In: Wound closure manual. Somerville: Ethicon Inc.; 2007.p. 15-6.

27. Teitelbaum S. The purse-string suture. Plast Reconstr Surg 1998;101:1748-9.

28. Kim YH, Yoon HW, Chung S, Chung YK. Reconstruction of cutaneous defects of the nasal tip and alar by two different methods. Arch Craniofac Surg 2018;19:260-3.

29. Kim ES, Heo JW, Yang CE, Kim J, Kim SW. Correction of a nasal soft triangle deficiency as a complication of augmentation rhinoplasty. Arch Craniofac Surg 2021;22:161-3.

30. Kim KP, Sim HS, Choi JH, Lee SY, Lee DH, Kim SH, et al. The versatility of cheek rotation flaps. Arch Craniofac Surg 2016;17: 190-7. 